\title{
PROMOÇÃO DA SAÚDE: BENEFÍCIOS ATRAVÉS DA DANÇA
}

\author{
HEALTH PROMOTION: BENEFITS THROUGH DANCE \\ PROMOCIÓN DE LA SALUD: BENEFICIOS A TRAVÉS DE LA DANZA
}

Recebido: 04/09/2014
Aprovado: $12 / 06 / 2015$
Luana Foroni Andrade ${ }^{1}$

Marli Aparecida Reis Coimbra ${ }^{2}$

Michele Viviene Carbinatto ${ }^{3}$

Mário Alfredo Silveira Miranzi ${ }^{4}$

Leila Aparecida Kauchakje Pedrosa ${ }^{5}$

O objetivo deste estudo foi relatar a vivência, perspectivas e benefícios da dança em um projeto de extensão universitária fundamentada na Política Nacional de Promoção da Saúde (PNPS). Trata-se de um relato de experiência surgido a partir da disciplina de um curso de mestrado junto ao projeto de extensão que reafirmou a dança e a atividade física como ferramentas importantes na busca por melhores condições de saúde e bem-estar. Os três eixos analisados foram: perspectiva, benefícios e vivência, apontando a dança como uma importante ferramenta na busca por melhores condições de saúde, ressaltando benefícios como: diminuição da dor, melhoria na autoestima e redução da timidez, aumento da sensação de bem estar e da capacidade de superação, melhora nos relacionamentos interpessoais, maior rendimento acadêmico e aumento no cuidado com o corpo.

Descritores: Dança; Promoção da saúde; Movimento.

The aim of this study was to report the experience, perspectives and benefits of dance in a university extension project based on the National Health Promotion (PNPS) of Brazil. This is an experience report emerged from the discipline of a master course with the extension project which reaffirmed dance and physical activity as important tools in the quest for better health and wellness. The three axes analyzed: perspective, benefits and, experience, reaffirmed the dance as an important tool in the quest for better health, emphasizing benefits such as decreased pain, improved self-esteem and reducing shyness, increase sense of well being and ability to overcome, improved interpersonal relationships, increased academic performance and increase in body care. Descriptors: Dancing; Health promotion; Movement.

El objetivo de este trabajo es presentar la experiencia, las perspectivas y los beneficios de la danza en un proyecto de extensión universitaria sobre la base de la Política Nacional de Promoción de la Salud (PNPS) brasileña. Se trata de un relato de experiencia que surgió de la disciplina de un curso de maestria con el proyecto de ampliación que reafirmó la danza y la actividad física como herramientas importantes en la búsqueda de una mejor salud y bienestar. Los tres ejes analizados: perspectiva, benefícios y experiencia de los beneficios, reafirmó la danza como una herramienta importante en la búsqueda de una mejor salud, subrayando beneficios, tales como: disminución del dolor, mejora de la autoestima y redución en la timidez, aumento de la sensación de bienestar y capacidad de superación, mejora de las relaciones interpersonales, mayor rendimiento académico y aumento en el cuidado del cuerpo.

Descriptores: Baile; Promoción de la salud; Movimiento.

\footnotetext{
${ }^{1}$ Terapeuta Ocupacional. Mestre em Educação Física. Professora Substituta pelo curso de Terapia Ocupacional da Universidade Federal do Triângulo Mineiro (UFTM).

${ }^{2}$ Enfermeira. Especialista em Enfermagem do Trabalho. Especialista em Docência do Ensino Superior. Mestre em Atenção à Saúde.mmarlimerlin@gmail.com

3Educadora Física. Doutora em Educação Física. Docente da Escola de Educação Física e Esportes da Universidade de São Paulo.mcarbinatto@yahoo.com.br

${ }^{4}$ Odontólogo. Doutor em Saúde Coletiva. Docente do Departamento de Medicina Social da UFTM. mmiranzi@mednet.com.br 5Enfermeira. Doutora em Saúde Coletiva. Professora Associada do Programa de Pós Graduação em Atenção à Saúde da UFTM. leila.kauchakje@enfermagem.uftm.edu.br
} 


\section{INTRODUÇÃO}

O $s$ documentos emitidos a partir de programas e projetos do governo no âmbito do Sistema Único de Saúde (SUS) com o objetivo de propor alternativas de promover saúde à população, como a Política Nacional de Promoção da Saúde (PNPS), apresentam eixos importantes para a reflexão sobre saúde e o que a permeia. A promoção da saúde é o processo de capacitação das pessoas para descobrirem meios de atingir melhores condições de vida e menor propensão às doenças ${ }^{1}$. A PNPS assim é uma tentativa do Ministério da Saúde, em consonância com os princípios do SUS, juntamente com gestores federais, estaduais e principalmente os municipais, em divulgar e alocar meios financeiros e orçamentários na implementação de propostas de saúde 2 .

Os principais eixos apontados pela PNPS são: alimentação saudável, práticas corporais/atividade física, ambiente sustentável, prevenção do uso de tabaco, álcool e outras drogas, assim como prevenção da violência e cultura da paz. A partir destes, o estudo em questão, enfatizou o eixo práticas corporais/atividade física, destacando que a utilização do termo práticas corporais permite ampliar concepções e perspectivas em relação à saúde através do olhar sobre o homem e seu corpo, valorizando novas práticas em saúde ${ }^{2}$, transpondo uma visão reducionista compreendida apenas pelo termo atividade física, que em uma linguagem científica poderia remeter a percepção desta, como apenas o que envolve gastos energéticos.

As práticas corporais/atividade física compreendem na atenção primária à saúde e na comunidade em geral ações que mapeiam e apoiam os serviços ofertando atividades como caminhadas, prescrição de exercícios, práticas lúdicas, esportivas e de lazer; capacitação dos trabalhadores de saúde; inclusão de pessoas com deficiências e pacto com os gestores do SUS, em busca de melhorias ambientais e aumento nos níveis de atividade física populacionais ${ }^{2}$.

Estas ações buscam ainda constituir mecanismos de sustentabilidade; organizar os serviços de saúde de forma a desenvolver iniciativas de aconselhamento; estimular a inserção e o fortalecimento dessas atuações já existentes no campo das práticas corporais em saúde; bem como desenvolver estudos e formular metodologias capazes de produzir evidências e comprovar a efetividade de estratégias de práticas corporais/atividades físicas no controle e na prevenção das doenças crônicas não transmissíveis ${ }^{2}$.

0 que se pode perceber é que a atenção sobre o sujeito passa a ser considerada também diante da influência de vários aspectos na qualidade de vida e nas condições de saúde deste, reconhecendo que inúmeras práticas corporais como a dança, tai chi chuan, yoga, ginásticas orientadas, podem contribuir para modos de vida mais saudáveis.

A dança tem sido utilizada como uma importante estratégia nos estudos sobre a relação do homem com seu corpo. Apresenta benefícios ao exigir do sujeito desde a organização dos movimentos do corpo, noção de espaço externo, trabalho com cinestesia e campo visual ${ }^{3}$. Um estudo apontou, ao comparar bailarinas com mulheres que não praticavam dança ${ }^{3}$, que a necessidade de adequar a postura corporal durante os movimentos e as posições estáticas, de acordo com o ritmo, interagindo com os movimentos do corpo e com os das pessoas a sua volta, influenciaram positivamente na imagem corporal destas, ao favorecer aos participantes uma satisfação corporal. Através do movimento e experimentação do corpo há uma maior estruturação quanto à experiência de si mesmo no mundo, bem como a promoção do resgate de sentimentos oprimidos que podem interferir na imagem corporal e consequentemente em sua qualidade de vida.

0 processo de saúde e adoecimento dos indivíduos é resultado dos modos de organização e da produção de trabalho, e da sociedade em determinado contexto histórico, onde o aparato biomédico não consegue intervir. 0 desafio da PNPS é conscientizar a população da necessidade de prevenir doenças e viver melhor, direcionando-a a co-responsabilização, além 
da avaliação do empenho dos gestores, profissionais de saúde, neste tipo de atenção.

Visando processos educativos em saúde é fundamental preparar o homem para a preservação de seu bem-estar biopsicossocial, refletindo inclusive sobre mudanças de atitude. Assim, estimular a prática de atividades como a dança vai de encontro aos objetivos da PNPS.

Diante do exposto, este estudo tem por objetivo relatar a vivência, perspectivas e benefícios da dança em um projeto de extensão universitária fundamentada na PNPS.

\section{MÉTODO}

0 estudo caracteriza-se por um relato de experiência surgido a partir da disciplina de Promoção e Proteção da Saúde do Mestrado em Atenção à Saúde da Universidade Federal do Triângulo Mineiro (UFTM) junto ao projeto de extensão Grupo Experimental de Dança (GED) desenvolvido pelo curso de Educação Física da mesma instituição e pertencente ao projeto "O SENTIDO DA DANÇA", aspecto vivência do praticante (aprovação CEP/UFTM n.2144).

0 mesmo foi fundamentado na PNPS no eixo prática corporal/atividade física enfatizando as ações de intersetorialidade e mobilização de parceiros na busca por incentivar práticas corporais em saúde na comunidade.

0 projeto de extensão Grupo Experimental de Dança (GED) teve início em março de 2011 com três objetivos fundamentais: capacitar novos professores para o trabalho com a dança, possibilitar e massificar a prática da dança e ampliar a linguagem artístico-cultural da comunidade UFTM. Atualmente o GED conta com uma coordenação geral e cinco monitores, todos da Educação Física e atende, diretamente, cerca de 90 alunos, advindos de diferentes cursos e setores da instituição e também da comunidade externa.

As aulas do projeto acontecem no Centro Educacional da UFTM uma vez por semana. 0 conteúdo básico programado para todas as aulas (dança do ventre, jazz, ritmos, dança de salão, ballet) são divididos em algumas partes fundamentais: preparação física (alongamento), conhecimento técnico da modalidade, criação e/ou exercícios coreográficos e relaxamento. Como não há seleção para as aulas, as turmas são bastante heterogêneas e por isso a elaboração e organização de aula é um grande desafio para os monitores.

Porém, vale destacar que seja ela qual formato escolhido a dança possui em sua essência a ordenação dos movimentos no tempo e no espaço; é a válvula de liberação de um processo interiorizado e se constitui como importante caminho para a expressão de sentimentos e desejos ${ }^{4}$.

As informações deste estudo foram coletadas na dinâmica de grupo do GED, com jovens do sexo feminino com idades entre 18 e 24 anos, acadêmicas dos cursos de graduação de duas universidades (seis do curso de educação física e duas do curso de matemática da UFTM e duas do curso de engenharia química de uma universidade particular, totalizando dez alunas). Ressaltase que o GED é aberto à comunidade, quando não preenchidas as vagas pelos alunos e funcionários da UFTM.

A proposta foi concretizada após as aulas destas alunas que participavam do projeto há mais de um semestre e, portanto, experienciaram o trabalho em sua plenitude, ou seja, aulas e apresentação no festival semestral de dança da universidade, organizado pelos monitores do projeto. As entrevistas ocorreram após as aulas de jazz, durante o mês de outubro de 2012.

Ressalta-se que são obrigatórios formatos avaliativos pautados em conceitos formativos e processuais aos projetos de extensão da UFTM e, a proposta do GED é justamente elucidar vivências sensíveis no trato com o corpo e sua relação consigo mesmo, com os outros e com o mundo. Neste sentido, em todos os grupos as "rodas de conversas" são realizadas no início do semestre (identificar e compreender o grupo de trabalho), antes da preparação coreográfica (para que todos participem e opinem no processo de construção artística, o que ocorre após cerca de dois meses de aula) e, no final do semestre, no qual opiniões, 
sugestões e críticas são expostas e ajustadas para o semestre seguinte.

Todavia, a roda de conversa relatada neste artigo teve caráter excepcional ao compreender e analisar as falas e observações das alunas a partir dos objetivos da PNPS de "valorizar e otimizar o uso dos espaços públicos de convivência e de produção de saúde para o desenvolvimento e, "estimulo à alternativas inovadoras e socialmente inclusivas/contributivas das ações de promoção da saúde"2.

Assim, para realização da pesquisa foram considerados três eixos norteadores das discussões na dinâmica de grupo do GED: eixo perspectiva, eixo benefícios e eixo vivência. 0 eixo perspectiva apresentou as motivações do aluno ao ingressar no projeto e o que o aluno buscava no grupo. 0 eixo benefícios considerou as mudanças que o aluno observava no seu cotidiano. Enquanto que para o eixo vivência, relacionou-se a percepção do aluno sobre o grupo e a participação daquele nesta atividade.

\section{RESULTADOS}

Foram evidenciados no estudo importantes aspectos que envolvem a relação do homem com seu corpo na busca por uma melhor qualidade de vida.

Em relação ao eixo perspectiva observou-se que o contato com as alunas do GED despertou-as para falar de suas expectativas, seus sonhos realizados, como entrar no palco e vencer a timidez, superarse dia após dia. 0 destaque para buscar a dança foi relacionada a fatores diversos: relaxamento, postura, alongamento para auxiliar na correção e tratamento de problemas de saúde como a escoliose, bem como busca por atividade física que antes já havia tido experiências positivas.

No eixo benefícios as alunas do GED deixaram claro o aprimoramento de habilidades cognitivas; sensação de renovação com menos dores lombares; sensação de bem estar; diminuição da timidez e melhora no relacionamento interpessoal; aumento do rendimento acadêmico; melhora na autoestima e capacidade de superação, bem como maior envolvimento e cuidado com o corpo. 0 único malefício destacado foi à dor, devido à exigência do corpo quanto a movimentos de alto impacto, sendo mesmo assim, exposto como algo pequeno diante dos benefícios, e até esquecido durante as aulas.

No eixo vivências, a dança foi relatada como uma importante ferramenta que oferece, em sua dinâmica, diferentes impressões. 0 acolhimento, a valorização e o respeito à individualidade entre as participantes, o compromisso pessoal e envolvimento do grupo acrescidos da experiência que a dança oferece na troca interpessoal e em uma melhor relação com o corpo, foram transmitidos como percepções importantes na motivação e incentivo à participação de práticas, como a dança na busca por melhores condições de saúde e bem estar.

\section{DISCUSSÃO}

Ao longo dos anos a dança tem proporcionado ao homem a capacidade de interagir com o meio, manifestar sentimentos e melhorar a função cognitiva e a autoestima, seja pelo desenvolvimento do relacionamento interpessoal, de movimentos do corpo e interação com o outro, da cultura e de aspectos emocionais, sendo que este tipo de modalidade favorece habilidades intelectuais e o raciocínio lógico ${ }^{5}$. Este fato foi evidenciado pelas alunas do GED, participantes deste estudo, em que a percepção da importância da dança no desenvolvimento da inteligência emocional e do autocontrole foram reafirmadas.

0 eixo perspectiva identificou que a busca pela dança foi relacionada a fatores diversos, sendo que relaxamento, melhor postura e alongamento para auxiliar na correção e tratamento de problemas de saúde como a escoliose, busca por uma atividade física foram destacados. Estes resultados corroboram outros estudos que mostram que a saúde tem sido relatada como um dos principais motivos para a prática da dança, aliada ao prazer e estados de ânimo ${ }^{6}$, assim como a procura por condicionamento físico, bem estar e sociabilização ${ }^{7}$, destacando-se também, que através da dança 
proporciona-se sensação de bem estar, inclusão em grupo, reduz a ansiedade, gera responsabilidade mútua, promove saúde e o desenvolvimento da função motora, equilíbrio, habilidade musical e criatividade ${ }^{5}$.

No eixo benefícios da dança, foi relatada sensação de renovação e a diminuição de dores lombares. Há estudos que evidenciam a dança como fator de proteção para dores osteomusculares como a fibromialgia ${ }^{8}$.

Ainda foram relatados a melhora no relacionamento interpessoal no eixo benefícios, bem como acolhimento, valorização, inclusão em grupo, respeito à individualidade, compromisso pessoal, envolvimento do grupo, experiência na troca interpessoal no eixo vivências.

Ao trazerem estes relatos as alunas ressaltam a dança também como uma ferramenta de comunicação. Na dança tornase possível reconhecer a linguagem do corpo, que fala sem o som das palavras, é o corpo que se apresenta e se expande ao mundo para conhecê-lo, reconhecê-lo e dele melhor se relacionar ${ }^{9}$. Favorece o relacionamento interpessoal ao promover o contato corporal, interação com os outros e desenvolvimento biopsicossocial ${ }^{10}$. Estudos indicam também que as atividades corporais em grupo desencadeiam ainda a amizade entre os indivíduos, reduzindo o isolamento social ${ }^{11} \mathrm{e}$ que ainda, proporcionam benefícios intensos ao indivíduo, inclusive quando aplicada em outros ambientes, fato observado na ginástica laboral com melhora do humor e diminuição do estresse, e integração entre colegas $^{12,13}$.

Nessa linha, as atividades de práticas corporais em grupo, têm sido relatadas por auxiliarem na promoção da saúde e estarem em consonância com a proposta política do SUS. Isto se deve por contribuir com a qualidade de vida das pessoas, por envolver o bem estar e capacidade de compreensão/participação, instruindo para que o indivíduo tenha responsabilidades $\mathrm{e}$ aprenda a lidar com as próprias necessidades e expectativas através de movimentos do corpo como a dança ${ }^{2,5}$. Por oferecerem múltiplas possibilidades de contato com o mundo, propicia interação, comunicação, movimentação corporal, diante de uma atuação física no ambiente ${ }^{14}$. Pensa-se corpo compreendendo as manifestações culturais expressivas nas diferentes relações humanas ${ }^{15}$, assim como as consequências destas nas condições de saúde.

No eixo benefícios foram destacados também aprimoramento de habilidades cognitivas, sensação de bem estar, diminuição da timidez, aumento do rendimento acadêmico, melhora na autoestima e capacidade de superação, bem como maior envolvimento e cuidado com o corpo.

Em consonância com estes resultados Brasileiro e Marcassa $^{15}$ confirmam estes achados, ao afirmarem que a linguagem do corpo possibilita conhecer melhor a si mesmo e o mundo que nos cerca, criando novas possibilidades para expressar, inserir e intervir no meio. A busca pelo conhecimento mais profundo de si e do mundo, transforma e renova realidades em mudanças simples no cotidiano. Estas por sua vez, repercutem beneficamente em hábitos mais saudáveis e em uma melhor qualidade de vida. Guimarães e Fernades ${ }^{7}$ destacam que a dança traz um estilo de vida mais saudável, trabalha os domínios do comportamento humano (psicomotor, socioafetivo e, perceptivo e cognitivo) através do movimento corporal, passando a ser um caminho na busca por maiores índices de qualidade de vida e saúde.

Reforça-se ainda que, por elencar diversas capacidades de movimento e flexibilidade, além de estimular a memória recente e a concentração, a dança favorece a qualidade de vida.

Diante deste mesmo prisma, ressalta-se que a pesquisa em questão soma-se a outras que trazem que ao iniciar a dança o sujeito traz sentimentos emergidos de seu cotidiano, sendo a partir da música e da troca de olhares com os outros integrantes que esses aspectos subjetivos sofrem interferência com a prática de atividades físicas. Estas reafirmam melhorias importantes na autoestima e na autoconfiança, maior capacidade de relaxamento, melhora na qualidade do sono, diminuindo fatores cruciais no gerenciamento do estresse 
diário ${ }^{16}$, como destacado neste estudo. Adeptos de práticas corporais apresentam resultados como: menor constância nas mudanças de humor, diminuição da ansiedade e da depressão, sensação de estar mais jovens e dispostos, refletindo positivamente em diversos aspectos que promovem melhoria na qualidade de vida ${ }^{14}$.

Destaca-se que a proposta em promover encontros a fim de dar vozes aos sujeitos desse projeto foi importante ao apresentar os resultados aqui apontados, reafirmando que iniciativas como essa podem ter impacto positivo nas condições de bem estar e saúde das pessoas. Todavia afirma-se que um número maior de encontros e uma coleta de informações mais aprofundada sobre esses sujeitos poderiam ampliar as informações angariadas e as discussões apresentadas, suscitando olhares ainda mais profundados sobre a percepção dessas pessoas.

Considera-se que é preciso identificar, refletir e divulgar estudos na área da saúde que tratam o corpo como realmente humano, pautados, sobretudo na identificação e superação de antigos paradigmas impostos na ciência, na saúde e, então, na atuação profissional ${ }^{17}$. Deve-se perceber o corpo em sua totalidade, exigindo das diversas áreas do conhecimento uma intervenção que abarque suas necessidades biológicas, sociais, históricas, políticas e culturais, com profissionais comprometidos a exercer essa descoberta de um corpo que fala, pensa, vive e sente. $E$, a dança, pode trazer à tona essas questões, tão minimizadas na formação profissional, como um todo.

\section{CONCLUSÃO}

Esta experiência reafirma a dança e a atividade física como ferramentas importantes na busca por melhores condições de saúde e bem-estar, bem como, os benefícios da prática ao destacar melhorias como a diminuição da dor, melhora na autoestima e da capacidade de superação, aumento na sensação de bem estar; redução da timidez e melhora no relacionamento interpessoal; aumento do rendimento acadêmico e aumento no cuidado com o corpo.

Esta pesquisa ao relatar uma experiência divulga práticas corporais e as mudanças proporcionadas pela dança no cotidiano e nas diversas esferas que compreendem o homem.

\section{REFERÊNCIAS}

1. Westphal MF. Promoção da saúde e a qualidade de vida. In: Rocha AA, Cesar CLG. Saúde pública: bases conceituais. São Paulo: Atheneu; 2008, p. 149-163.

2. Ministério da Saúde (Br); Secretaria de Vigilância em Saúde; Secretaria de Atenção à Saúde. Política Nacional de Promoção da Saúde. 2ed. Brasília: Ministério da Saúde; 2007.

3. Fonseca CC, VecchiRL, Gama EF. A influência da dança de salão na percepção corporal. Motriz Rev Educ Fís. 2012; 18(1):200-7.

4. Ossoma PA. Educação pela dança. São Paulo: Summus; 1988.

5. Montezuma MAL, Rocha MV, Busto RM, Fujisa WD. Adolescentes com deficiência auditiva: a aprendizagem da dança e a coordenação motora. Rev Bras Educ Esp. 2011;17(2):321-34.

6. Machado JR, Liberali R, Netto MIA, Mutarelli MC. Fatores motivacionais em adolescentes para à prática da dança na escola. Encontro. 2011; 14(21):77-89.

7. Guimarães ACA, Fernandes S, Simas JPN. Do diagnóstico à ação: programa ritmo e movimento: dançando para um estilo de vida ativo. Rev Bras Ativ Fís Saúde. 2011; 16(2):177-80.

8. Carbonell-Baeza A, Aparicio VA, MartinsPereira CM, Gatto-Cardia CM, Ortega FB, Huertas FJ, et al. Efficacy of biodanza for treating women with fibromyalgia. J Altern Complement Med. [Internet]. 2010 [citado em 12 abr 2013]; 16(11):1191-200. DOI: 10.1089/acm.2010-0039.

9. Garaudy R. Dançar a vida. Rio de Janeiro: Nova Fronteira; 1980.

10. Sousa NCP, Caramaschi S. Contato corporal entre adolescentes através da dança de salão na escola. Motriz Rev Educ Fís. 2011; 17(4):618-29. 
11. Oliveira LC, Pivoto EA, Vianna PCP. Análise dos resultados de qualidade de vida em idosos praticantes de dança sênior através do SF-36. Acta Fisiatrica. 2009; 16(3):101-4.

12. Walsh IAP, Bertoncello D, Frizzo HCF, Alves SG, Santos WLM. Percepção dos servidores de um Hospital de Clínicas sobre os efeitos da Ginástica Laboral. REFACS [Internet]. 2014 [citado em 15 jun 2013]; 2(1):22-7. Disponível http://www.uftm.edu.br/revistaeletronica/i ndex.php/refacs/article/view/1144/998 13. Mejía FM. Efectos de la danza terapéutica em el control del estrés laboral em adultos entre 25 y 50 años. Hacia Promoc. Salud. 2011; 16(1):156-74.

14. Lima DM, Neto Silva NA. Danças brasileiras e psicoterapia: um estudo sobre efeitos terapêuticos. Psicol Teor Pesq. 2011; 27(1):41-8.
15. Brasileiro LT, Marcassa LP. Linguagens do corpo: dimensões expressivas e possibilidades educativas da ginástica e da dança. Pro-Posições. 2008; 19(3):195-207.

16. Catib NOM, Schwartz GM, Christofoletti DFA, Santiago DRP, Caparroz GP. Estados emocionais de idosos nas danças circulares. Motriz Rev Educ Fís. 2008; 14(1):41-52.

17. Carbinatto MV, Moreira WW. Corpo e saúde: a religação dos saberes. Rev Bras Cienc Esporte. 2006; 27(3):185-200.

\section{CONTRIBUIÇÕES}

Todos os autores tiveram iguais contribuições na descrição da experiência, na análise dos diálogos, bem como na redação final do artigo. 